\title{
The Effects of Anterior Chamber Depth to Endothelial Cell Loss Using Tranversal Phacoemulsification
}

\author{
Budiman ${ }^{1,2}$ \\ ${ }^{1}$ Department of Ophthalmology, Faculty of Medicine Universitas Padjadjaran, Bandung, Indonesia \\ ${ }^{2}$ Cataract and Refractive Surgery Unit, Cicendo National Eye Center, Bandung, Indonesia \\ Email: dr.bujournal@gmail.com
}

How to cite this paper: Budiman (2021) The Effects of Anterior Chamber Depth to Endothelial Cell Loss Using Tranversal Phacoemulsification. Open Journal of Ophthalmology, 11, 240-248.

https://doi.org/10.4236/ojoph.2021.113019

Received: July 16, 2021

Accepted: August 17, 2021

Published: August 20, 2021

Copyright $\odot 2021$ by author(s) and Scientific Research Publishing Inc. This work is licensed under the Creative Commons Attribution International License (CC BY 4.0).

http://creativecommons.org/licenses/by/4.0/ (c) (i) Open Access

\begin{abstract}
Background: Phacoemulsification surgery is the most frequent cataract surgery performed in developed countries because of its effectiveness and safety. However, some degree of endothelial loss is inevitable in any type of cataract surgery, including phacoemulsification. Anterior chamber depth (ACD) could be considered as one of important anatomical parameters for preserving endothelial loss from the mechanical and thermal damage that can occur during the procedure. Purpose: To evaluate the effects of ACD on endothelial cell density, hexagonality, coefficient variation (CV) and central corneal thickness (CCT) at one and four weeks after phacoemulsification using transversal ultrasound. Method: This was a prospective study conducted at Cicendo National Eye Hospital Indonesia from April to August 2018, where we performed phacoemulsification in 148 patients with ACD $<3 \mathrm{~mm}$ group, $\mathrm{ACD} \geq 3 \mathrm{~mm}$ group. Specular microscopy examination was performed prior to phacoemulsification and repeated at one and four weeks after surgery. The changes in endothelial density, percentage of hexagonality, CV and CCT between two groups were evaluated and compared. Result: Mean (SD) endothelial density in ACD $<3 \mathrm{~mm}$ group and $\mathrm{ACD} \geq 3 \mathrm{~mm}$ group at 1-week evaluation was 1761.9 (503.3) and 1966.1 (530.6) cells $/ \mathrm{mm}^{2}$ respectively, with $p$ value 0.030 . At 4 -week evaluation, endothelial cell density in ACD $<3 \mathrm{~mm}$ group and ACD $\geq 3 \mathrm{~mm}$ group was 1537.8 (504.9) and 1798.7 (554.0) cells $/ \mathrm{mm}^{2}$ respectively, with $p$ value 0.010 . There was no statistical difference regarding hexagonality, CV and CCT between both groups at 1-week and 4-week evaluation. Endothelial density changes percentage also higher in ACD $<3 \mathrm{~mm}$ group at 1-week and 4-week evaluation. Conclusion: Endothelial cell density in $\mathrm{ACD}<3 \mathrm{~mm}$ group was significantly lower compared to ACD $\geq 3$ $\mathrm{mm}$ group at 1-week and 4-week evaluation after phacoemulsification.
\end{abstract}




\section{Keywords}

Anterior Chamber Depth, Endothelial Cell, Cataract, Phacoemulsification

\section{Introduction}

Phacoemulsification is the most frequent cataract surgery performed in many countries [1] [2]. It is popular amongst cataract surgeons due to better visual acuity improvement, smaller incision, lower surgically induced astigmatism, and faster healing compared to other cataract extraction techniques. Some degree of endothelial loss is inevitable in any type of cataract surgery including phacoemulsification. Corneal endothelial cells are at risk during phacoemulsification due to ultrasound energy, mechanical trauma due to contacts with lens fragments or instruments, irrigation flow and fluid movements. Corneal endothelial cells are hexagonal and unable to replicate. Trauma in corneal endothelial leads to enlargement and migrations of endothelial cells to cover the damage area. Severe loss of endothelial cells will impact its function as physical barrier and active pumps, leads to increased corneal thickness and decreased corneal transparency [3] [4] [5].

Severe loss of endothelial cells could lead to corneal decompensation which is vision-threatening complication after phacoemulsification surgery. Thus, it is important for cataract surgeon to evaluate any preoperative, intraoperative, and postoperative risk factors that could lead to excessive endothelial cell loss. Several studies have reported that hard nucleus density, high ultrasound energy, long phacoemulsification time, the phacoemulsification technique, and large infusion volumes increase the risk of endothelial cell loss after phacoemulsification [4] [5] [6] [7] [8]. Phacoemulsification surgery is performed in a limited, confined space; however, securing adequate surgical space during surgery can decrease the risk of excessive endothelial loss as a result of the phacoemulsification procedure. Thus, anatomical factors, such as adequate anterior chamber depth (ACD), are important for preserving these cells from the mechanical and thermal damage that can occur during the procedure. However, several studies reported that ACD did not affect endothelial cell loss after phacoemulsification surgery [6] [7] [8]. This study aims to evaluate the effects of ACD on endothelial cell density, hexagonality, coefficient variation $(\mathrm{CV})$ and central corneal thickness (CCT) at one and four weeks after phacoemulsifcation using transversal ultrasound.

\section{Materials and Methods}

This prospective study was conducted at Cataract and Refractive Surgery Unit at Cicendo National Eye Hospital from April to August 2018. Inclusion criteria were patients with cataract grade II-IV, age more than 30 years old, and underwent phacoemulsification with IOL implantation. Patients with preoperative intraocular pressure $(\mathrm{IOP})>21 \mathrm{mmHg}$, endothelial cells density $<1.500 / \mathrm{mm}^{2}$, 
history of intraocular surgery, pseudoexfoliative syndrome, zonnular weakness, patients without IOL implantation and had complication during or after the surgery were excluded from this study. We divided the patients into two groups; group with ACD $3 \mathrm{~mm}$ or more and group ACD depth less than $3 \mathrm{~mm}$. We measured ACD using Zeiss IOL Master (Carl Zeiss AG, Oberkochen, Germany). To evaluate corneal endothelial density, hexagonality, CV and CCT preoperatively, 1 week after surgery and 4 weeks after surgery we used specular microscope (TopCon SP-3000P).

All patients underwent phacoemulsification by two experienced cataract surgeons (BU and ES) using WhiteStar Signature PRO (Abbott Medical Optic [AMO], Santa Ana, CA) phacoemulsification machine. We administered tropicamide $1 \%$ eye drop prior surgery to get adequate pupil dilatation. During surgery, intracameral adrenaline 1:100,000 can be added to get maximal dilatation of the pupil. Phacoemulsification procedure was following: topical anesthesia on the corneal with tetracaine hidrochloride $2 \%$, aseptic and antiseptic with povidone iodine, sterile drape and speculum were applied, creation of three plane clear corneal incision with $2.75 \mathrm{~mm}$ keratome in temporal area, injection of Healon-5 viscoadaptive to form the anterior chamber, continuous curvilinear capsulorrhexis with cystotome, hydrodissection and hydrodelineation, side port incision with superblade 15-degree, phacoemulsification using phaco-chop or stop-and-chop technique, aspiration and irrigation of epinucleus and cortex, Healon-5 viscoleastic injection, IOL implantation within capsular bag, aspiration and irrigation of viscoelastic, hydration of main incision.

All patients received standard postoperative treatment included ciprofloxacin tablet $2 \times 500 \mathrm{mg}$ per oral, levofloxacin eye drops 6 times daily, and prednisolone acetate eye drops 6 times daily. We evaluated the patients at 1 week and 4 weeks after surgery with specular microscope (Topcon SP-3000P) to assess endothelial cell density, hexagonality, CV and CCT postoperatively. The percentage decrease of endothelial cell was calculated as: endothelial cell loss (\%) = [(postoperative $\mathrm{ECD}$ - preoperative $\mathrm{ECD}$ )/preoperative $\mathrm{ECD}] \times 100$.

Statistical analysis was performed using SPSS Version 22 (IBM, Inc., Chicago, IL) program. Normality of the data was tested using Shapiro-Wilk test. Comparison of endothelial cell density, hexagonality, CV and CCT preoperative and postoperative between the groups were calculated using unpaired $t$ test, $t$ test or Mann-Whitney test where appropriate. A p-value less than 0.05 was considered as statistically significant.

\section{Results}

One-hundred-forty-eight patients were included in this study; consist of $103 \mathrm{pa}$ tients in $\mathrm{ACD} \geq 3 \mathrm{~mm}$ group and 45 patients in $\mathrm{ACD}<3 \mathrm{~mm}$ group. The sample size was determined by calculating the sample size to test the mean difference between two unpaired data, so that we acquired minimal sample size of 40 for each group. There was no statistical difference between the numbers of male and 
female patients in both groups. Both surgeons also had the same amounts of patients. Mean (SD) age in ACD $\geq 3 \mathrm{~mm}$ group was 59.3 (10.8) years, meanwhile in ACD $<3$ mm group was 65.2 (8.1) years respectively (Table 1). There was no statistically significant difference in mean (SD) endothelial cell density, hexagonality, CV and CCT between both group prior surgeriesss (Table 2).

We found endothelial cell density in ACD $<3 \mathrm{~mm}$ group was significantly lower compared to $\mathrm{ACD} \geq 3 \mathrm{~mm}$ group at 1 -week and 4-week evaluation. Mean (SD) endothelial density in ACD $<3 \mathrm{~mm}$ group and $\mathrm{ACD} \geq 3 \mathrm{~mm}$ group at 1 week evaluation was 1761.9 (503.3) and 1966.1 (530.6) cells $/ \mathrm{mm}^{2}$ respectively, with $\mathrm{p}$ value 0.030 (Table 3 ). At 4 -week evaluation, endothelial cell density in ACD $<3 \mathrm{~mm}$ group and ACD $\geq 3 \mathrm{~mm}$ group were 1537.8 (504.9) and 1798.7 (554.0) cells $/ \mathrm{mm}^{2}$ respectively, with $\mathrm{p}$ value 0.010 . Meanwhile, there was no statistical difference regarding hexagonality, CV and CCT between both groups at 1-week and 4-week evaluation (Table 4).

Table 1. Demographic Status.

\begin{tabular}{|c|c|c|c|}
\hline & \multicolumn{2}{|c|}{ Anterior Chamber Depth } & \multirow{2}{*}{$\mathbf{P}$} \\
\hline & $\geq 3 \mathrm{~mm}(\mathrm{n}=103)$ & $<3 \mathrm{~mm}(\mathrm{n}=45)$ & \\
\hline Gender & & & $0.783^{*}$ \\
\hline Male & 62 & 26 & \\
\hline Female & 41 & 19 & \\
\hline Age (years) & & & $0.030^{* *}$ \\
\hline Mean (SD) & $59.3(10.8)$ & $65.2(8.1)$ & \\
\hline Surgeon & & & $0.944^{*}$ \\
\hline $\mathrm{BU}^{* * *}$ & 51 & 22 & \\
\hline $\mathrm{ES}^{\star * \star *}$ & 52 & 23 & \\
\hline
\end{tabular}

${ }^{\star}$ chi square test; ${ }^{* \star}$ Mann-Whitney test; SD: standard deviation; ${ }^{\star * \star}$ Budiman, MD ${ }^{\star * * *}$ Sugiarti, MD.

Table 2. Mean Endothelial Density, Hexagonality, CV and CCT before Surgery.

\begin{tabular}{|c|c|c|c|}
\hline & \multicolumn{2}{|c|}{ Anterior Chamber Depth } & \multirow{2}{*}{$\mathbf{P}$} \\
\hline & $\geq 3 \mathrm{~mm}(\mathrm{n}=103)$ & $<3 \mathrm{~mm}(\mathrm{n}=45)$ & \\
\hline Endothelial density (cells $/ \mathrm{mm}^{2}$ ) & & & $0.268^{\star}$ \\
\hline Mean $(\mathrm{SD})$ & $2523.1(354.5)$ & $2454.9(314.5)$ & \\
\hline Median (range) & $2486.5(1666.6-3609.6)$ & $2420.9(1692-3042)$ & \\
\hline Hexagonality (\%) & & & $0.711^{\star}$ \\
\hline Mean (SD) & $51.9(9.7)$ & $52.6(10.7)$ & \\
\hline Median (range) & $51.8(25-79)$ & $50.6(35-88)$ & \\
\hline $\mathrm{CV}(\%)$ & & & $0.446^{* x}$ \\
\hline Mean (SD) & $37.4(5.7)$ & $38.2(6.4)$ & \\
\hline Median (range) & $36.9(27.2-65.5)$ & $38.1(23.8-52.8)$ & \\
\hline $\mathrm{CCT}(\mu \mathrm{m})$ & & & $0.897^{\star}$ \\
\hline Mean (SD) & $513.0(30.2)$ & $513.7(28.4)$ & \\
\hline Median (range) & $511.6(425-601)$ & $510(457-599)$ & \\
\hline
\end{tabular}

*unpaired $\mathrm{t}$ test; ${ }^{* *}$ Mann-Whitney $\mathrm{U}$ test; CV: coefficient of variance; CCT: central corneal thickness; SD: standard deviation. 
Table 3. One-week Evaluation after Phacoemulsification.

\begin{tabular}{|c|c|c|c|}
\hline & \multicolumn{2}{|c|}{ Anterior Chamber Depth } & \multirow{2}{*}{$\mathbf{P}$} \\
\hline & $\geq 3 \mathrm{~mm}(\mathrm{n}=103)$ & $<3 \mathrm{~mm}(\mathrm{n}=45)$ & \\
\hline Endothelial density (cells $/ \mathrm{mm}^{2}$ ) & & & $0.030^{*}$ \\
\hline Mean (SD) & $1966.1(530.6)$ & $1761.9(503.3)$ & \\
\hline Median (range) & $1953.2(802-3156)$ & $1756.9(923.9-2827.6)$ & \\
\hline Hexagonality (\%) & & & $0.256^{*}$ \\
\hline Mean (SD) & $42.6(16.0)$ & $45.8(14.7)$ & \\
\hline Median (range) & $44.1(0-100)$ & $46(0-80)$ & \\
\hline $\mathrm{CV}(\%)$ & & & $0.989^{*}$ \\
\hline Mean (SD) & $41.6(7.8)$ & $41.6(6.6)$ & \\
\hline Median (range) & $40.9(25.7-59.0)$ & $40.9(24.7-55.0)$ & \\
\hline $\mathrm{CCT}(\mu \mathrm{m})$ & & & $0.481^{\star \star}$ \\
\hline Mean (SD) & $536(46.7)$ & $537.8(44.7)$ & \\
\hline Median (range) & $526.2(436-601)$ & $540(461-730)$ & \\
\hline
\end{tabular}

*unpaired $\mathrm{t}$ test; ${ }^{* *}$ Mann-Whitney $\mathrm{U}$ test; $\mathrm{CV}$ : coefficient of variance; CCT: central corneal thickness; SD: standard deviation.

Table 4. Four-week Evaluation after Phacoemulsification.

\begin{tabular}{|c|c|c|c|}
\hline & \multicolumn{2}{|c|}{ Anterior Chamber Depth } & \multirow{2}{*}{$\mathbf{P}$} \\
\hline & $\geq 3 \mathrm{~mm}(\mathrm{n}=90)$ & $<3 \mathrm{~mm}(\mathrm{n}=40)$ & \\
\hline Endothelial density (cells $/ \mathrm{mm}^{2}$ ) & & & $0.010^{* *}$ \\
\hline Mean (SD) & $1798.7(554.0)$ & $1537.8(504.9)$ & \\
\hline Median (range) & $1827(736.8-2908)$ & $1539.5(739.6-2612.1)$ & \\
\hline Hexagonality (\%) & & & $0.535^{\star}$ \\
\hline Mean (SD) & $46.4(15.5)$ & $44.6(45.4)$ & \\
\hline Median (range) & $47.1(0-100)$ & $45.4(0-76)$ & \\
\hline $\mathrm{CV}(\%)$ & & & $0.293^{* *}$ \\
\hline Mean (SD) & $39.7(8.4)$ & $38.5(8.8)$ & \\
\hline Median (range) & $38.2(25.1-69.1)$ & $37.1(25.0-62.3)$ & \\
\hline $\mathrm{CCT}(\mu \mathrm{m})$ & & & $0.965^{\star *}$ \\
\hline Mean (SD) & $519.4(32.9)$ & $520.6(33.9)$ & \\
\hline Median (range) & $519.5(440-641)$ & $517(465-612)$ & \\
\hline
\end{tabular}

*unpaired t test; ${ }^{* *}$ Mann-Whitney $\mathrm{U}$ test; CV: coefficient of variance; CCT: central corneal thickness; SD: standard deviation.

At 1-week and 4-week evaluation there was statistically different in endothelial density changes percentage between $\mathrm{ACD}<3 \mathrm{~mm}$ group and ACD $\geq 3 \mathrm{~mm}$ group, with $\mathrm{p}$ value 0.032 and 0.024 respectively. We found no difference in hexagonality, CV and CCT changes percentage between both groups at 1-week and 4-week evaluation (Table 5).

\section{Discussion}

It is inevitable that endothelial cell loss will occur during any cataract surgery 
Table 5. Percent Changes in Endothelial Density, Hexagonality, CV and CCT.

\begin{tabular}{|c|c|c|c|}
\hline & \multicolumn{2}{|c|}{ Anterior Chamber Depth } & \multirow{2}{*}{$\mathbf{P}^{*}$} \\
\hline & $\geq 3 \mathrm{~mm}$ & $<3 \mathrm{~mm}$ & \\
\hline \multicolumn{4}{|c|}{ Decrease of endothelial density (\%) } \\
\hline 1 week (median, range) & $19.4(-20.6-67.2)$ & $29(20.3-63.0)$ & 0.032 \\
\hline 4 week (median, range) & $25.6(-10-72.4)$ & $38.2(-8.2-68.3)$ & 0.024 \\
\hline \multicolumn{4}{|l|}{ Decrease of hexagonality (\%) } \\
\hline 1 week (median, range) & $10(-150-100)$ & $17.6(-59.1-100)$ & 0.725 \\
\hline 4 week (median, range) & $7.9(-150-100)$ & $13(-61.1-100)$ & 0.402 \\
\hline \multicolumn{4}{|l|}{ Increase of CV (\%) } \\
\hline 1 week (median, range) & $8.8(-39-72.1)$ & $12(-29.6-66.8)$ & 0.882 \\
\hline 4 week (median, range) & $3.1(-36.1-90.8)$ & $-5.9(-44.8-72.1)$ & 0.152 \\
\hline \multicolumn{4}{|l|}{ Increase of CCT (\%) } \\
\hline 1 week (median, range) & $2.5(-100-35.5)$ & $3.7(-6.6-38)$ & 0.230 \\
\hline 4 week (median, range) & $0.3(-10.5-21.6)$ & $0.6(-8.2-20.7)$ & 0.783 \\
\hline
\end{tabular}

${ }^{*}$ Mann-Whitney test; CV: coefficient of variance; CCT: central corneal thickness.

techniques including phacoemulsification. Several studies already identified several risk factors that can influence endothelial cell loss due to phacoemulsification. Several parameters such as ultrasound power, phaco time, irrigation turbulence flow, nucleus density and mechanical contact with surgery instruments, nuclear fragments and IOL were associated with endothelial loss [6] [8] [9]. Several anatomical parameters such as anterior chamber depth and axial length also correlated with increase of endothelial cell loss. Phacoemulsification was done in a limited space, so the stability of anterior chamber will provide the surgeon enough space for surgery manipulation. Thus ACD should be taking into consideration as one of important anatomical parameters in phacoemulsification [8] [9].

In this study, there was no significant difference in endothelial cell density, hexagonality, $\mathrm{CV}$ and CCT prior to surgery between $\mathrm{ACD}<3 \mathrm{~mm}$ group and $A C D \geq 3 \mathrm{~mm}$ group prior to surgery (Table 2). At one week and four weeks after surgery, we found significant decrease of endothelial cell in ACD $<3 \mathrm{~mm}$ group, with $p$ value 0.030 and 0.010 respectively. Meanwhile there was no significant difference regarding hexagonality, $\mathrm{CV}$ and CCT between ACD $<3 \mathrm{~mm}$ group and $\mathrm{ACD} \geq 3 \mathrm{~mm}$ at one week and four weeks after surgery.

There have been several studies reported the correlation between ACD and endothelial cell loss with contradicting results. Reuschel et al. [8] reported that ACD was not identified as one of the risk factors for endothelial cell loss after phacoemulsification. Jung et al. [10] reported a comparison between nanophthalmos and relative anterior microphthalmos with a control group. He found a higher endothelial loss of $14.22 \% \pm 18.45 \%$ in nanophthalmic eyes (mean ACD $1.82 \pm 0.31 \mathrm{~mm}$ ) compared to an $11.57 \% \pm 11.34 \%$ within relative anterior microphthalmic eyes (ACD $1.87 \pm 0.24 \mathrm{~mm}$ ) and $7.61 \% \pm 8.77 \%$ in their normal 
control eyes (mean ACD $2.70 \pm 1.31 \mathrm{~mm}$ ). However, the results were not statistically significant. Walkow et al. [7] reported that shorter axial length and longer phaco time as risk factors for endothelial cell loss, because small confined surgical space in short eyes increases the risk of endothelial touch by surgical instruments and lens fragments. However, the authors could not demonstrate a relationship between ACD and endothelial cell loss. O'Brien et al. [1] reported $\mathrm{ACD}$ and axial length were not related with endothelial cell loss during phacoemulsification, due to an adequate surgical space could be formed during the surgery using irrigation flow. In addition, Cho et al. [10] reported in a prospective study that risk factors for endothelial cell loss after phaoemulsification were different according to ACD. In short ACD eyes, long corneal tunnel length can be considered as one of the risk factors for endothelial cell loss.

In shallow anterior chamber, phaco tip will be closer to corneal endothelial during surgery compared to eyes with deep ACD, so that corneal endothelial cells could be more susceptible to transversal ultrasound energy, heat energy, surgical instruments, and friction with lens fragments [7] [8] [9]. For this particular reason, we hypothesized that eyes with shallow ACD could have more endothelial cell loss that eyes with deep ACD. In this study, the significantly higher loss of endothelial cell in ACD $<3 \mathrm{~mm}$ group was not accompanied with significant increase of hexagonality, CTT and decrease of CV.

Direct trauma of corneal endothelium due to phacoemulsification procedure results endothelial loss, meanwhile the decrease of hexagonality represent as the parameter of corneal endothelial wound healing due to trauma. Due to unable to regenerate, corneal endothelial cell will stretch and cover surrounding damaged areas after surgery. Endothelial density measurement alone was not enough to evaluate the function of corneal endothelial after intraocular surgery. Polymegatism which is represented by coefficient of variation and polymorphism which is represented by hexagonality are more sensitive to evaluate whether the corneal endothelial is in a state of stress or not [11] [12] [13].

We use transversal phacoemulsification technology in this study, which is using a straight or curved needle tip vibrating at $38 \mathrm{kHz}$ and move side-to-side as well as longitudinal movement, and has both peristaltic and venturi fluidics. Transversal ultrasound-power modulation is a technological development that minimizes chatter from the nuclear fragments that are being emulsified. This type of modulation results in the ability of a side-to-side movement that may reduce the frictional heat generation noted with traditional longitudinal-only movement. ${ }^{9}$ These developments in oscillation, together with the advancement of micropulse-energy delivery, have resulted in reduced repulsion of the lens material during aspiration and improved followability, which is the beneficial tendency of nuclear fragments to be aspirated in a relatively feathery and continuous fashion [14] [15] [16].

However, this study has several limitations. The sample in two groups was not similar in number, there were two surgeons who did the surgery and we did not 
evaluate other intraoperative parameters such as phaco time, the amount of BSS used, and surgery time. In addition, patients with systemic disease such as diabetes mellitus were also enrolled in this study. The role of diabetes mellitus to endothelial cell loss in phacoemulsification was still controversial. Since, there are several studies have been evaluated the effect of diabetes mellitus to endothelial cell loss after phacoemulsification, but the results are still contradicting [11] [17] [18] [19] [20] [21].

\section{Conclusion}

There was statistically significant decrease in endothelial cell loss at one and four weeks after surgery in patients with $\mathrm{ACD}<3 \mathrm{~mm}$ group. There was no significant difference in hexagonality, $\mathrm{CV}$ and $\mathrm{CCT}$ at one and four weeks after phacoemulsification percentage between $\mathrm{ACD}<3 \mathrm{~mm}$ group and ACD $\geq 3 \mathrm{~mm}$ group. Shallow ACD can cause significant endothelial loss compared to deep ACD due to trauma caused by phacoemulsification procedure. Therefore, the surgeon should take into consideration shallow ACD as an important anatomical parameter for phacoemulsification procedure in order to minimize endothelial loss.

\section{Conflicts of Interest}

The author declares no conflicts of interest regarding the publication of this paper.

\section{References}

[1] O’Brien, P.D., Fitzpatrick, P., Kilmartin, D.J., et al. (2004) Risk Factors for Endothelial Cell Loss after Phacoemulsification Surgery by a Junior Resident. Journal of Cataract \& Refractive Surgery, 30, 839-843. https://doi.org/10.1016/S0886-3350(03)00648-5

[2] Dan-Mircea, S., Andreaa-Maria, F., Adriana, S., et al. (2017) Endothelial Cell Loss to the Hyperopic Patients during Phacoemulsification. Romanian Journal of Ophthalmology, 61, 256-260. https://doi.org/10.22336/rjo.2017.46

[3] Jaggernath, J., Gogate, P., Moodley, V., et al. (2014) Comparison of Cataract Surgery Techniques: Safety, Efficacy, and Cost-Effectiveness. European Journal of Ophthalmology, 24, 520-526. https://doi.org/10.5301/ejo.5000413

[4] Gogate, P., Ambardekar, P., Kulkarni, S., et al. (2010) Comparisson of Endothelial Cell Loss after Catract Surgery: Phacoemulsification versus Manual Small-Incision Cataract Surgery. Journal of Cataract \& Refractive Surgery, 36, 247-253. https://doi.org/10.1016/j.jcrs.2009.09.023

[5] Faramarzi, A., Javadi, M.A., Karimian, F., et al. (2011) Corneal Endothelial Cell Loss during Phacoemulsification: Bevel-Up versus Bevel-Down Phaco Tip. Journal of Cataract \& Refractive Surgery, 37, 1971-1976. https://doi.org/10.1016/j.jcrs.2011.05.034

[6] Hwang, H.B., Lyu, B., Yim, H.B., et al. (2015) Endothelial Cell Loss after Phacoemulsification According to Different Anterior Chamber Depths. Journal of Ophthalmology, 2015, Article ID: 210716. https://doi.org/10.1155/2015/210716

[7] Walkow, T., Anders, N. and Klebe, S. (2000) Endothelial Cell Loss after 
Phacoemulsification: Relation to Preoperative and Intraoperative Parameters. Journal of Cataract \& Refractive Surgery, 26, 727-732. https://doi.org/10.1016/S0886-3350(99)00462-9

[8] Reuschel, A., Bogatsch, H., Oertel, N., et al. (2015) Influence of Anterior Chamber Depth, Anterior Chamber Volume, Axial Length, and Lens Density on Postoperative Endothelial Cell Loss. Graefe's Archive for Clinical and Experimental Ophthalmology, 253, 745-752. https://doi.org/10.1007/s00417-015-2934-1

[9] Cho, Y.K., Chang, H.S. and Kim, M.S. (2010) Risk Factors for Endothelial Cell Loss after Phacoemulsification: Comparison in Different Anterior Chamber Depth Groups. Korean Journal of Ophthalmology, 24, 10-15.

https://doi.org/10.3341/kjo.2010.24.1.10

[10] Jung, K.I., Yang, J.W., Lee, Y.C., et al. (2012) Cataract Surgery in Eyes with Nanophthalmos and Relative Anterior Microphthalmos. American Journal of Ophthalmology, 153, 1161-1168. https://doi.org/10.1016/j.ajo.2011.12.006

[11] Hugod, M., Storr-Paulsen, A., Norregaard, J.C., et al. (2011) Corneal Endothelial Cell Changes Associated with Cataract Surgery in Patients with Type 2 Diabetes Mellitus. Cornea, 30, 749-753. https://doi.org/10.1097/ICO.0b013e31820142d9

[12] Nishida, T., Saika, S. and Morishige, N. (2017) Cornea and Sclera: Anatomy and Physiology. In: Mannis, M.J. and Holland, E.J., Eds., Cornea: Fundamentals, Diagnosis and Management, 4th Edition, Elsevier, New York, 1-22.

[13] Sayegh, R.R., Benetz, B.A. and Lass, J.H. (2017) Specular Microscopy. In: Mannis, M.J. and Holland, E.J., Cornea: Fundamentals, Diagnosis and Management, 4th Edition, Elsevier, New York, 160-179.

[14] Assil, K.K., Harris, L. and Cecka, J. (2015) Transverse vs. Torsional Ultrasound: Prospective Randomized Contralaterally Controlled Study Comparing Two Phacoemulsification-System Handpieces. Clinical Ophthalmology, 9, 1405-1411. https://doi.org/10.2147/OPTH.S86660

[15] Christakis, P.G. and Braga-Mele, R.M. (2012) Intraoperative Performance and Performance and Postoperative Outcome Comparison of Longitudinal, Torsional, and Transversal Phacoemulsification Machines. Journal of Cataract \& Refractive Surgery, 38, 234-241. https://doi.org/10.1016/j.jcrs.2011.08.035

[16] Tognetto, D., Cecchini, P., Leon, P., et al. (2012) Stroke Dynamics and Frequency of 3 Phacoemulsification Machines. Journal of Cataract \& Refractive Surgery, 38, 333-342. https://doi.org/10.1016/j.jcrs.2011.07.041

[17] Khan, A., Kose, S., Jharwal, M.K., et al. (2016) Comparison of Corneal Endothelial Cell Counts in Patients with Controlled Diabetes Mellitus (Type 2) and Non Diabetics after Phacoemulsification and Intraocular Lens Implantation. International Multispecialty Journal of Health, 2, 14-22.

[18] Elbassiouny, O., Khalil, A., Al Nahrawy, O., et al. (2017) Corneal Endothelial Changes in Correlation with Corneal Thickness after Phacoemulsification among Diabetic Patients. Advances in Ophthalmology \& Visual System, 7, 1-5. https://doi.org/10.15406/aovs.2017.07.00208

[19] Choo, M., Prakash, K., Samsudin, A., et al. (2010) Corneal Changes in Type II Diabetes Mellitus in Malaysia. International Journal of Ophthalmology, 3, 234-236.

[20] Yang, R., Sha, X., Zeng, M., et al. (2011) The Influence of Phacoemulsification on Corneal Endothelial Cells at Varying Blood Glucose Levels. Eye Science, 26, 91-95.

[21] He, X., Diakonis, V.F., Alavi, Y., et al. (2017) Endothelial Cell Loss in Diabetic and Nondiabetic Eyes after Cataract Surgery. Cornea, 36, 948-951.

https://doi.org/10.1097/ICO.0000000000001245 